\title{
Inhibitor effect of new azomethine derivative containing an 8-hydroxyquinoline moiety on corrosion behavior of mild carbon steel in acidic media
}

\author{
A. El yaktini, ${ }^{1}$ A. Lachiri, ${ }^{1}$ M. El Faydy, ${ }^{2}$ F. Benhiba, ${ }^{3}$ H. Zarrok, $^{3}$ \\ M. El Azzouzi, ${ }^{4}$ M. Zertoubi, ${ }^{1}$ M. Azzi, ${ }^{1}$ B. Lakhrissi ${ }^{2}$ and A. Zarrouk ${ }^{5^{*}}$ \\ ${ }^{1}$ Laboratoire Interface Matériaux Environnement, Faculté des Sciences, Université Hassan \\ II Casablanca, B.P 5366 Maârif Casablanca, Morocco \\ ${ }^{2}$ Laboratory of Agricultural Resources, Polymer and Process Engineering, Department of \\ Chemistry, Faculty of Sciences, Ibn Tofail University, Kenitra, Morocco \\ ${ }^{3}$ Laboratory of Separation Procedures, Faculty of Sciences, Ibn Tofail University, Kenitra, \\ Box 133, Kenitra, Morocco \\ ${ }^{4}$ LC2AME, Faculty of Sciences, Mohammed First University, PO Box 717, 60000 Oujda, \\ Morocco \\ ${ }^{5}$ Laboratory of Materials, Nanotechnology and Environment, Faculty of Sciences, \\ Mohammed V University, Av. IbnBattouta, Box 1014 Agdal-Rabat, Morocco \\ E-mail:azarrouk@gmail.com
}

\begin{abstract}
A new Azomethine derivative namely 5-(((4-hydroxybenzylidene)amino)methyl)quinolin-8-ol (HBHQ) was synthesized and identified by different spectroscopic methods. The product was assessed in the inhibition of corrosion of carbon steel (CS) in $1 \mathrm{M} \mathrm{HCl}$ using Tafel polarization, weight loss and electrochemical impedance spectroscopy. Their property anticorrosion is relative in concentrations and achieved $92 \%$ at the optimum concentration of $10^{-3} \mathrm{M}$. Polarization studies showed that that the newly synthesized inhibitor was of mixed type in nature. The EIS data bring that, the development of a protective layer of azomethine derivative increase the charge transfer resistance and decreases in the double layer capacitance of carbon steel in acid medium. The adsorption process at interface of carbon steel in hydrochloric acid by HBHQ was studied at different temperatures (298-338 K) by means of Tafel polarisation measurements. The adsorption of azomethine derivative on the carbon steel (CS) surface followed Langmuir adsorption isotherm and in order to discover the mode of adsorption process, various thermodynamic and activation parameters were evaluated. Quantum chemical calculations were performed using methods based on density functional theory (DFT/B3LYP) and Monte Carlo simulations (MCs). Indeed, the results obtained by this computation reflect a good agreement with the practical part.
\end{abstract}

Keywords: synthesis of azomethine, corrosion, carbon steel, electrochemical and gravimetric measurements, DFT, B3LYP, MCs.

Received: August 1, 2018. Published: November 22, 2018

doi: $\underline{10.17675 / 2305-6894-2018-7-4-9}$ 


\section{Introduction}

Corrosion presents a serious industrial problem in an aggressive environment and caused an important economic waste [1]. With a specific end goal to alleviate the corrosion of metal, different hindrance strategies have been created, for example, the utilization of protective coatings, the utilization of corrosion safe materials and the media of use control. Among these techniques, adding inhibitors to the aggressive medium is a standout amongst the most efficient and viable strategies [2-4]. The corrosion protection of inhibitor is linked with the compound structure [5]. For the most part, the organic molecules, containing hetero atoms, for example, sulfur, phosphorus, oxygen and nitrogen, display great inhibition performance [6]. This electron-rich group can give the lone pair of electrons to the electron deficient metal cations and therefore an adsorption on the metal surface by shaping a coordinate covalent bond (chemical adsorption) or by forming vander-Waals interactions (physical adsorption) between the metal and inhibitor [7-9].

The quinoline and Schiff's bases have gotten extensive consideration on their inhibition properties for metallic corrosion over the previous year's [10]. 8Hydroxyquinoline is a derived from quinoline compounds Consisting of pyridine and phenol rings, the presence of conjugated system, nitrogen and oxygen atom are probably going to encourage the adsorption of the molecule on the metal surface. The existing data about 8-hydroxyquinoline derivatives show good corrosion inhibition efficiencies [11-13].

Schiff bases are organic compounds demonstrated their power towards steel corrosion in acidic media resulting from the presence of their adsorptive $-\mathrm{HC}=\mathrm{N}$-group exhibiting lone pair of electrons on Nitrogen atoms and the planarity structure, they are easily synthesizable from the condensation of primary amines and carbonyl group [13,14].

Some Schiff bases inhibitors have been already detailed as powerful corrosion inhibitors for different metals in corrosive media, for example, Schiff bases containing thiophene substituents [15] and furoin thiosemicarbazone, but the Schiff bases containing 8-hydroxyquinoline have never exploited as a corrosion inhibitor and our research takes in this context [16].

Accordingly, the new Schiff's bases containing a 5-methyl-8-hydroxyquinoline motive was synthesized, purified and characterized by ${ }^{1} \mathrm{H}$ NMR,${ }^{13} \mathrm{C}$ NMR and elemental analysis. The corrosion behaviour of HBHQ has been elucidated by weight loss, potentiodynamic polarization and electrochemical impedance spectroscopy (EIS). Parallel with the experimental, theoretical calculations and Monte Carlo simulations are also performed to find a relationship structure-activity. 


\section{Experimental details}

\subsection{Inhibitor Synthesis}

\subsubsection{General Information}

The starting reagents and solvents are imported from Sigma-Aldrich, NMR $\left({ }^{1} \mathrm{H}\right.$ and $\left.{ }^{13} \mathrm{C}\right)$ spectra were registered using Bruker Avance $(300 \mathrm{MHz})$. The advancing of the reaction was followed by Thin-Layer Chromatography (TLC) using silica gel 60 F254 (E. Merck) plates). Elemental analyses were carried out by Elementar $\mathrm{CHN}$ VarioMicro Cube analyser.

\subsubsection{Chemical synthesis}

A mixture of 1 eq. of 5-aminomethyl-8-hydroxyquinoline, 1 eq. of 4-hydroxybenzaldehyde and 1 eq. of triethylamine in $20 \mathrm{~mL}$ of dried ethyl acetate was heated under stirring for $20 \mathrm{~h}$. After completion and cooling to room temperature, water $(50 \mathrm{~mL}+10 \mathrm{ml}$ of sodium bisulfite) was subsequently added and the product extracted. The combined organic phases were combined, dried over anhydrous sodium sulfate, filtered and evaporated. The obtained residue was purified by column chromatography with hexane/acetone (8:3 to $1: 9$ $\mathrm{v} / \mathrm{v})$. The synthesized compounds structures were confirmed by ${ }^{1} \mathrm{H}$ and ${ }^{13} \mathrm{C} \mathrm{NMR}$ and elemental analysis.
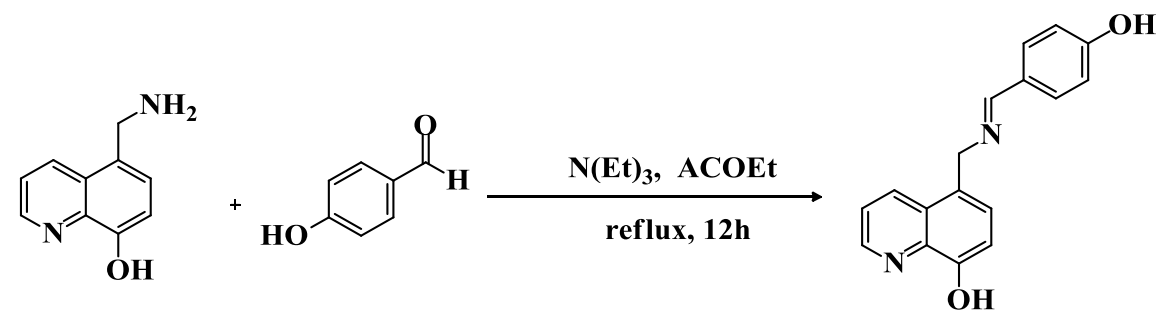

Scheme 1. Synthetic route of azomethine derivatives.

The analytical data of the both azomethine are:

For HBHQ: 5-(((4-hydroxybenzylidene)amino)methyl)quinolin-8-ol. Yield 56\%; m.p. $155-157^{\circ} \mathrm{C} .{ }^{1} \mathrm{H}$ NMR $(300 \mathrm{MHz}, \mathrm{DMSO}-\mathrm{d} 6), \delta \mathrm{ppm}=7.05-7.72(\mathrm{~m}, 7 \mathrm{H}$, quinoline and benzaldehyde), $4.19\left(\mathrm{~d}, 2 \mathrm{H}\right.$, quinoline $\left.-\mathrm{CH}_{2}-\mathrm{N}\right), 9.86(\mathrm{~s}, 1 \mathrm{H}, \mathrm{CH}=\mathrm{N}), 5.05(\mathrm{~s}, 2 \mathrm{H}$, $\mathrm{OH}), 8.58-8.83$ (m, 2H, quinoline). ${ }^{13} \mathrm{C}$ NMR (300 MHz, DMSO-d6), $\delta \mathrm{ppm}=66.02$ (quinoline $\left.-\mathrm{CH}_{2}-\mathrm{N}\right), 109.90-153.26(\mathrm{CH}$. $\mathrm{C}$ quinoline and benzene), $169.19(\mathrm{C}=\mathrm{N})$, $161.15(\mathrm{C}-\mathrm{OH})$. Elemental analysis for $\mathrm{C}_{17} \mathrm{H}_{14} \mathrm{~N}_{2} \mathrm{O}$ : Calcd. C, 73.37; H, 5.07; N, 10.07\%; Found: C, 73.40; H, 5. 10; N, 10.03\%.

All ${ }^{1} \mathrm{H}$ NMR, ${ }^{13} \mathrm{C}$ NMR spectra are attached in supplementary data.

\subsection{Materials}

The ingredients of working electrode (carbon steel) and their pre-treatment methods have been formerly described. The same thing with regard to the corrosive mediums [17]. The 
HBHQ was studied in a gap of concentration ranging from 0.001 to $10^{-6} \mathrm{M}$. The border of this interval are determined for each synthesized products by its solubility (for maximum concentration of azomethine derivatives) and by their low inhibiting properties (for the minimum concentration of azomethine derivatives).

\subsection{Corrosion assessment tests}

\subsubsection{Weight loss measurements}

Gravimetric experiments have been realized pursuant to the standard method A.S.T.M. G103 described beforehand [18]. The substrates of dimension $4 \times 1.5 \times 0.05 \mathrm{~cm}$ were chosen to perform the weight loss tests. In order to obtain the reproducible results, all experiments were repeated four times for each concentration.

\subsubsection{Electrochemical measurements}

Electrochemical studies were realized by means of an Autolab $400 \mathrm{ml}$ corrosion cell (CORR.CELL). To reach steady state potential, CS (carbon steel) electrode with a surface area of $1 \mathrm{~cm}^{2}$ as working electrode, a platinum (Pt) electrode as an auxiliary electrode, saturated calomel electrode (SCE) used as a reference electrode and a fine Luggin capillary was put near CS to decrease ohmic resistance were maintained throughout the period considered (30 $\mathrm{min})$ in a thermostat at $298 \pm 2 \mathrm{~K}$. The Tafel polarization was carried out at a scan rate of $0.5 \mathrm{mV} / \mathrm{sec}$.

Impedance measurement were effectuate at the steady state potential $\left(E_{\text {ocp }}\right)$, with a frequency interval from $100 \mathrm{kHz}$ down to $10 \mathrm{mHz}$, utilizing a small amplitude signals $(10 \mathrm{mV})$.

Electrochemical measurements were made with a PGZ 100 monitored by a PC supported by the VoltaMaster4 Software, and the obtained Nyquist plots were fitted employing ZView 3.3 software (Scribner Associates).

\section{Results and discussion}

\subsection{Gravimetric tests}

The newly compound of azomethine is first examined by gravimetric measurements at $298 \mathrm{~K}$ after $6 \mathrm{~h}$ of immersion. The corrosion rate $\left(C_{\mathrm{R}}\right)$ and protection efficiency $\eta_{\mathrm{g}}(\%)$ were established by virtue of the formulas 1 and 2 [19], respectively:

$$
\begin{gathered}
C_{\mathrm{R}}=\frac{G_{\mathrm{b}}-G_{\mathrm{a}}}{A t} \\
\eta_{\mathrm{g}}=\left(\frac{C_{R 0}-C_{R 1}}{C_{R 0}}\right) \times 100
\end{gathered}
$$

Where $G_{\mathrm{b}}$ and $G_{\mathrm{a}}$ represent the weight before and after immersion in the electrolyte, $C_{R 0}$ and $C_{R 1}$ describe the values of corrosion weight losses of CS in blank medium and inhibited solutions, respectively, $A$ the surface of CS and $t$ is the immersion time (h). 
The results of this study are summarized in Table 1. For both inhibitors, the corrosion rate and the inhibitory efficiency are presented for each concentration used.

Table 1. Corrosion data obtained by gravimetric technique at various concentrations of HBHQ and HQ in acidic media.

\begin{tabular}{ccccc}
\hline Medium & Conc. $(\mathbf{M})$ & $\boldsymbol{C}_{\mathbf{R}}\left(\mathbf{m g} / \mathbf{c m}^{\mathbf{2}} \mathbf{h}\right)$ & $\boldsymbol{\eta}_{\mathbf{g}}(\boldsymbol{\%})$ & $\boldsymbol{\theta}$ \\
\hline $1 \mathrm{M} \mathrm{HCl}$ & 0 & 0.750 & - & - \\
\hline \multirow{3}{*}{$\mathrm{HBHQ}$} & $10^{-3}$ & 0.060 & 92 & 0.92 \\
& $10^{-4}$ & 0.105 & 86 & 0.86 \\
& $10^{-5}$ & 0.150 & 80 & 0.80 \\
& $10^{-6}$ & 0.292 & 61 & 0.61 \\
\hline \multirow{2}{*}{$8-\mathrm{HQ}^{[17]}$} & $10^{-3}$ & 0.210 & 72.3 & 0.72 \\
& $10^{-4}$ & 0.270 & 64.5 & 0.64 \\
& $10^{-5}$ & 0.337 & 55.5 & 0.55 \\
& $10^{-6}$ & 0.383 & 49.0 & 0.49 \\
\hline
\end{tabular}

The examination of obtained results in Table 1 clearly shows that these compounds have good inhibitory properties of CS corrosion in $1 \mathrm{M} \mathrm{HCl}$ media. We likewise find that the corrosion rate diminishes while the protection effectiveness increments with the inhibitor concentration, and reaches a maximum value of $92 \%, 72 \%$ at optimum concentration, respectively for HBHQ and 8-HQ. The expansion in inhibitory efficiency with concentration proposes that this inhibitor adsorbs increasingly at the surface and covers the active sites of the metal surface and in this manner prompts the formation of a barrier that diminishes the reactivity of the metal [20].

In acidic condition, a small fraction of considered molecules is protonated as a result of lone pair electrons of nitrogen and oxygen atoms and progress toward becoming cations $\left(\mathrm{HBHQ}-\mathrm{H}^{+}\right.$, 8-HQ- $\left.\mathrm{H}^{+}\right)$and in this way adsorb through electrostatic connections with chloride $\left(\mathrm{Cl}^{-}\right)$ions. However, neutral form could shape bond with the orbital $\mathrm{d}$ of iron atoms, causing the displacement of water particles from the metal surface and $\mathrm{sp}^{2}$ electron sets separated $\mathrm{N}$ and $\mathrm{O}$ molecules and $\pi$-orbitals, blocking the active sites in the surface of the steel and thus diminishing the rate of corrosion. In order to comparing the effect of protection of HBHQ, we brought the inhibition effect of 8-HQ. The obtained difference in terms of inhibition between BDHQ and 8-HQ originates from the presence of the radical $\mathrm{R}$ focused on 8-hydroxyquinoline at 5 position, the presence of $\left(-\mathrm{CH}_{2}-\mathrm{N}=\mathrm{CH}-\mathrm{ph}-\mathrm{OH}\right)$ group which is classified as an electron donating group (+M, Mesomeric effect) which improves the protective effect [21]. 


\subsection{Adsorption isotherm}

The methods accessible for estimated the nature of the interactions between organic and metallic species are adsorption isotherms [22]. In this context, many models can be used to assess the adsorption process of HBHQ at working electrode surface as: Temkin, Frumkin and Langmuir; which are estimated according to the following equations [23]:

Temkin:

$$
e^{(-2 a \theta)}=b C_{\mathrm{oc}}
$$

Frumkin:

$$
\theta(1-\theta)^{-1} e^{(-2 a \theta)}=b C_{\mathrm{oc}}
$$

Langmuir:

$$
C_{\mathrm{oc}} \times \theta^{-1}=K_{\mathrm{d}}^{-1}+C_{\mathrm{oc}}
$$

Where $\theta$ characterized as the fraction of surface covered, $K_{\mathrm{d}}$ the constant of adsorption reaction and $C_{\mathrm{oc}}$ corresponding to the HBHQ concentration.

The current information demonstrates that the best fit is accomplished with Langmuir's isotherm for monolayer adsorption; the $\theta$ values acquired from gravimetric are given by:

$$
\theta=\frac{\eta_{\mathrm{g}}}{100}
$$

the variation of $C_{\mathrm{oc}} / \theta$ as function of $C_{\mathrm{oc}}$ exhibit a straight line (Figure 1) with linear coefficient $\left(R^{2}\right)$ close to one, implying that the adsorption of azomethine molecule on the $\mathrm{CS}$ is all around adapted to the Langmuir adsorption isotherm.

The constant $K_{\mathrm{d}}$ obtained by the fitting of Langmuir isotherm straight and is associated with Gibbs energy by the next relation.

$$
\Delta G_{\mathrm{d}}^{0}=-2.303 R T\left(\log _{10} 55.55+\log _{10} K_{\mathrm{d}}\right)
$$

In this formula, $R$ is the gas constant and 55.55 is the molar concentration of water.

The following Table 2 summarizes the different thermodynamic parameters.

Table 2. Thermodynamic parameters for the adsorption of HBHQ on CS in $\mathrm{HCl}$ electrolyte.

\begin{tabular}{cccc}
\hline Inhibitor & $\boldsymbol{R}^{\mathbf{2}}$ & $\boldsymbol{K}_{\mathrm{d}}\left(\mathbf{L ~ m o l}^{\mathbf{- 1}}\right)$ & $\Delta \boldsymbol{G}_{\mathrm{d}}^{\mathbf{0}}\left(\mathrm{kJ} \mathrm{mol}^{\mathbf{- 1}}\right)$ \\
\hline HBHQ & 0.99998 & 311660.46 & -42.68 \\
\hline
\end{tabular}

The negative estimations of $\Delta G_{\mathrm{d}}^{0}$ demonstrate that all the HBHQ inhibitor is firmly adsorbed on the CS surface. The considered $\Delta G_{\mathrm{d}}^{0}$ value as delineated in Table 2 is lower than $-40 \mathrm{~kJ} \mathrm{~mol}^{-1}$ which implies that the absorption process is of the chemisorption nature [24]. 


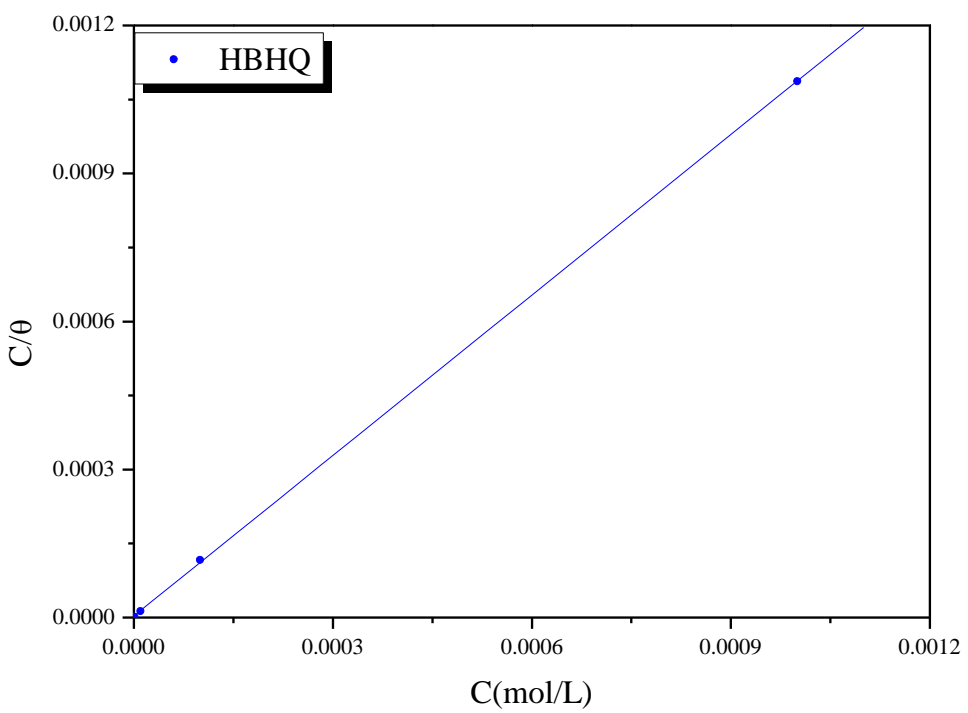

Figure 1. Langmuir adsorption isotherm plots for HBHQ on CS in aggressive media.

\subsection{Potentiodynamic polarization curves}

Figures 2 outline the Tafel curves of the CS in acid electrolyte at room temperature, in with and without of HBHQ at various concentrations. The curves were recorded after a holding time of the CS at the free corrosion potential for 30 minutes. As per these curves, I attract your thoughtfulness regarding that the addition of azomethine compound include a reduction both the cathodic and anodic current densities, this is more momentous given at optimum concentration.

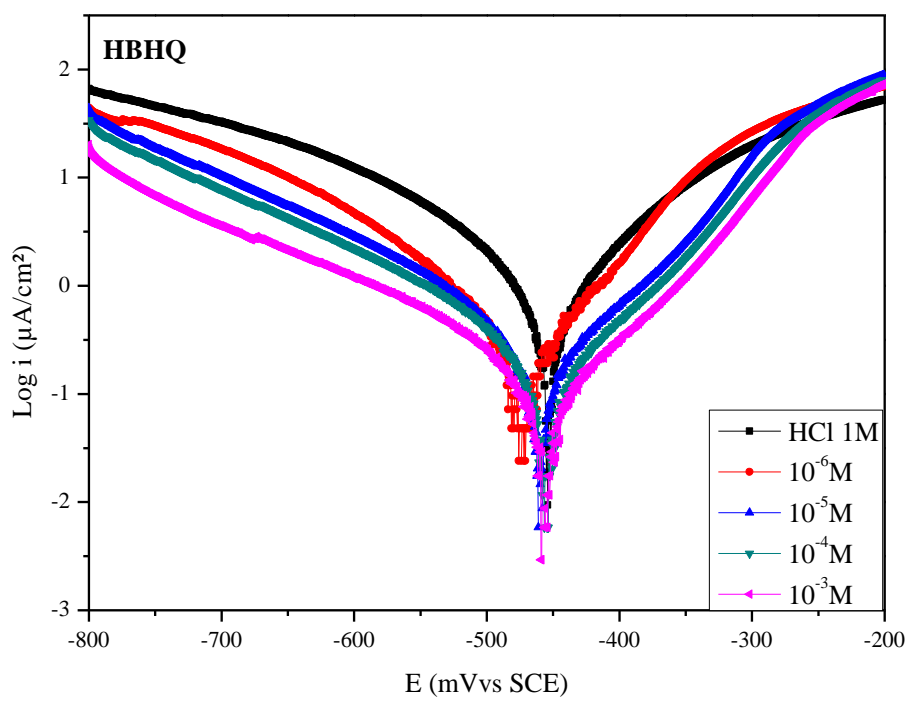

Figure 2. Tafel curves for CS at $298 \mathrm{~K}$ in electrolyte in the absence and presence of synthesized azomethine derivative. 
Various parameters got from Tafel curves are organized in Table 3. Concerning the inhibition efficiencies for every concentration of HBHQ were found by use of Eq. (8):

$$
\eta_{\text {Tafel }}=\left(1-\frac{i_{\text {inhb }}}{i_{\text {blank }}}\right) \times 100
$$

Where $i_{\text {blank }}$ and $i_{\text {inhb }}$ are the corrosion current densities of blank and inhibited environment respectively.

Table 3. Various electrochemical parameters of CS in $1 \mathrm{M} \mathrm{HCl}$ in the absence and presence of synthesized azomethine derivative.

\begin{tabular}{ccccccc}
\hline Medium & $\begin{array}{c}{[\boldsymbol{C}]} \\
(\mathbf{m o l} / \mathbf{L})\end{array}$ & $\begin{array}{c}-\boldsymbol{E}_{\mathbf{c}} \\
(\mathbf{m V} \mathbf{v s .} \mathbf{C S E})\end{array}$ & $\begin{array}{c}\boldsymbol{i}_{\mathbf{c o r r}} \\
\left(\boldsymbol{\mu} \mathbf{A} / \mathbf{c m}^{2}\right)\end{array}$ & $\begin{array}{c}-\boldsymbol{\beta}_{\mathbf{c}} \\
\left(\mathbf{m V} \mathbf{d e c}^{-\mathbf{1}}\right)\end{array}$ & $\begin{array}{c}\boldsymbol{\beta}_{\mathbf{a}} \\
\left(\mathbf{m V} \mathbf{d e c}^{-\mathbf{1}}\right)\end{array}$ & $\begin{array}{c}\eta_{\text {Tafel }} \\
(\boldsymbol{\%})\end{array}$ \\
\cline { 2 - 7 } Blank & 1 & 454 & 1947.7 & 182.9 & 151.8 & - \\
\hline \multirow{3}{*}{ HBHQ } & $10^{-3}$ & 457 & 215.6 & 180.8 & 91.9 & 89 \\
& $10^{-4}$ & 456 & 330.5 & 176.1 & 97.9 & 83 \\
& $10^{-5}$ & 461 & 426.7 & 169.7 & 89.3 & 78 \\
& $10^{-6}$ & 474 & 832.5 & 162.5 & 113.7 & 58 \\
\hline
\end{tabular}

As shown in Table 3, the expanded of protective properties $\eta_{\text {Tafel }}$ with inhibitor concentration demonstrates that the organic compound works by hindering the active sites on CS. However, displacement of the corrosion potential $\left(E_{\mathrm{c}}\right)$ did not demonstrate any huge change in the field considered ( $\max \leq 20 \mathrm{mV} v s$. SCE) indicating that the HBHQ is mixed type inhibitor [25]. Both the anodic and cathodic current densities have diminished in the presence of the synthesized azomethine derivative, the variation in cathodic Tafel slopes $\beta_{\mathrm{c}}$ suggesting that that HBHQ affect the cathodic reactions and the change in anodic Tafel slants $\beta_{\mathrm{a}}$ after addition of HBHQ which proposes that the studied compound can influence kinetics of the anodic reaction. From the structure of HBHQ, the nitrogen atoms have a non-bonding pair of electrons. This may support the development of $\mathrm{Fe}^{2+}-\mathrm{HBHQ}$ complex compound and accordingly changes the dissolution mechanism of iron [26]. On the other hand, it is obvious that the azomethine inhibitor perform great protection capacity all along corrosion potential until $-290 \mathrm{mV}$ ( $v s$. SCE). However, for potential more positive than $-290 \mathrm{mV}$ ( $v s$. SCE), the presence of HBHQ don't modify the current $v s$. potential characteristics obviously. This potential is typically characterized as desorption potential [27], this behavior could be due to the important dissolution of working electrode, prompt the desorption of adsorbed particles. In this case, the equilibrium is shifted to the desorption reaction. 


\subsection{Electrochemical Impedance Spectroscopy (EIS)}

The Nyquist curves in the presence and the absence of newly synthesized azomethine in $\mathrm{HCl}$ electrolyte are exhibited in Figure 3. It is noticed that the got spectra without and with newly azomethine are as a single semi-circle, and their size fluctuates relying upon both the concentration of HBHQ, which is granted to charge transfer process and one time constant. Also, it very well may be watched that the impedance loops don't yield idealize semicircles. Due to the "dispersing effect", which has been linked with surface roughness and/or inhomogeneity of the steel surfaces and adsorption of inhibitors the centers of the circles are under the real axis $[28,29]$.

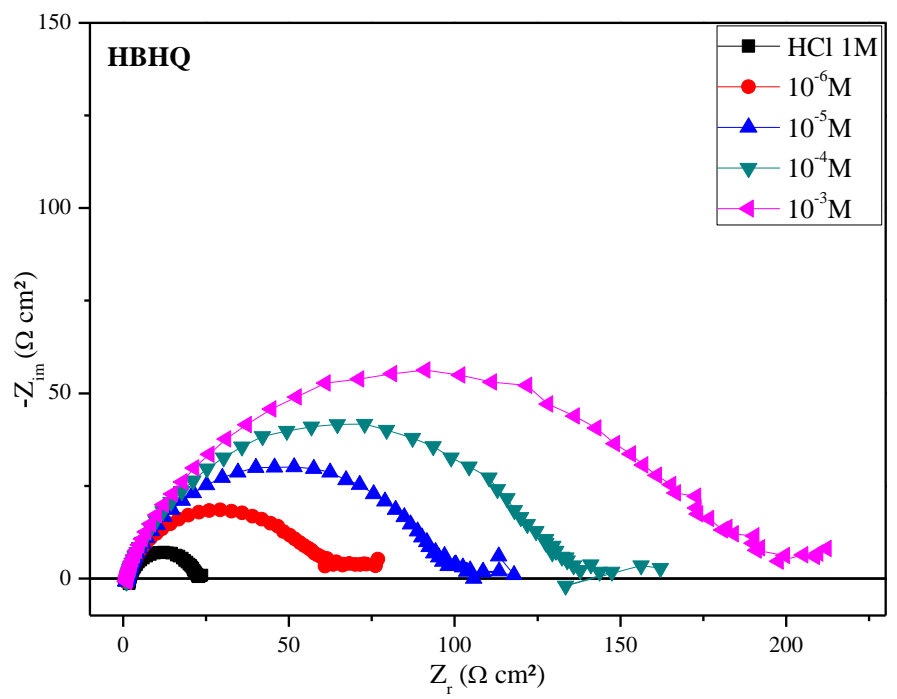

Figure 3. Nyquist plot for $\mathrm{CS}$ in $1 \mathrm{M} \mathrm{HCl}$ electrolyte in absence and presence of azomethine molecules.
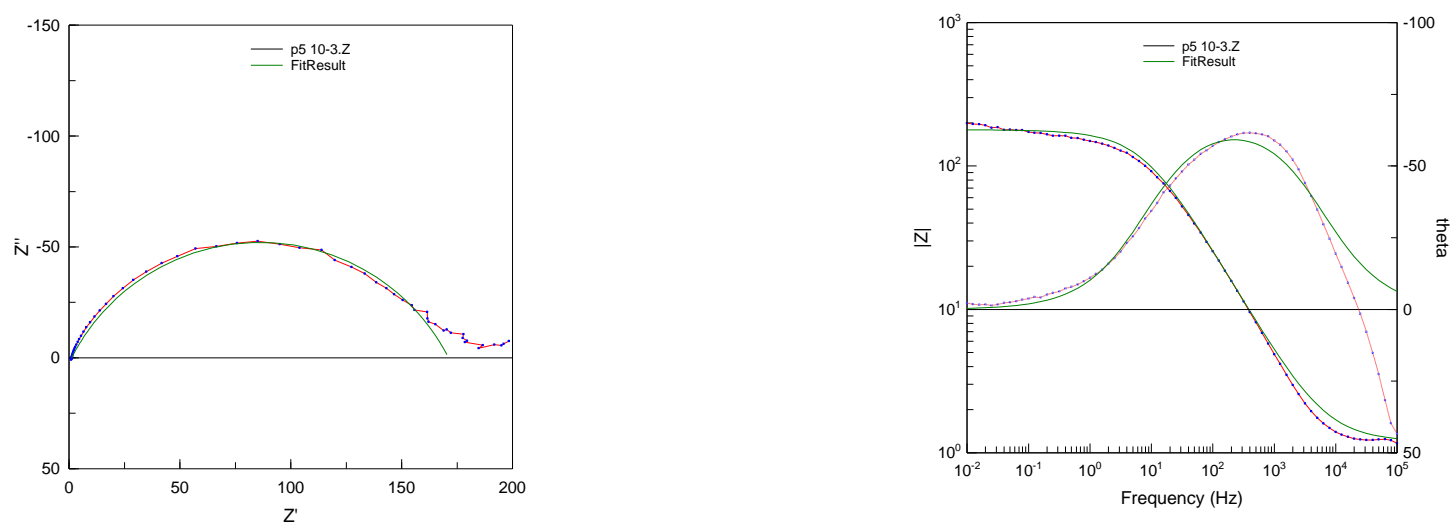

Figure 4. Representative example of EIS Nyquist and Bode diagrams simulated in $1 \mathrm{M} \mathrm{HCl}$ with $10^{-3} \mathrm{M}$ of HBHQ. 
Various EIS parameters were accomplished by the simulation of all impedance spectra through the appropriate equivalent circuit (Figure 5).

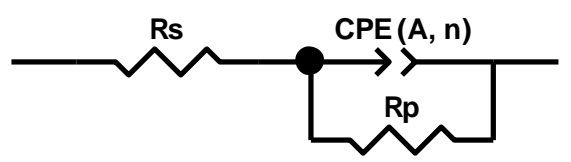

Figure 5. The related equivalent circuit used for fitting of all obtained impedance spectra.

The components of the circuit can be named as: $R_{\mathrm{S}}$ is the solution resistance, which is in series with a constant phase element (CPE (A)) that is in parallel with the polarization resistance $\left(R_{\mathrm{p}}\right)$. It permits utilizing CPE component to examine the inhibitive film properties on metallic surface and expressed by [30]:

$$
Z_{\mathrm{CPE}}=A^{-1}(i \omega)^{-n}
$$

Where $A$ is a constant of CPE in $\left(\Omega^{-1} \mathrm{~s}^{n} \mathrm{~cm}^{-2}\right), n$ is the CPE exponent for entire number of $n=1,0,-1$, identifying the phase shift and $w$ is a angular frequency in $\left(\mathrm{rad} \mathrm{s}^{-1}\right)$ which is calculated as the product of $2 \pi$ and the frequency, the CPE, is substituted for the perfect capacitive component to give a more precise fit to account for the depressed nature of the semicircles.

The CPE, $n$ and $R_{\mathrm{p}}$ are used to calculate the double layer capacitance $\left(C_{\mathrm{dl}}\right)$ by next Eq.

$$
C_{\mathrm{dl}}=\left(A R_{\mathrm{p}}^{1-n}\right)^{1 / n}
$$

The term of protection efficiency, $\eta_{\Omega}(\%)$, is explicit via the last formula

$$
\eta_{\Omega}=\frac{R_{\mathrm{pm}}-R_{\mathrm{pb}}}{R_{\mathrm{pm}}} \times 100
$$

In which $R_{\mathrm{pb}}$ and $R_{\mathrm{pm}}$ are the polarization resistance of working electrode in $\mathrm{HCl}$ electrolyte without and with newly synthesised azomethine, respectively.

The utilization of equivalent circuit permits to given a good fit for all Nyquist spectra and give the values of fitted parameters in with and without of examined Schiff bases (Fig. 4), the examination of the EIS results (Table 4) uncovers that the value of $R_{\mathrm{p}}$ expands more in the inhibited system than in the uninhibited system and achieves a most extreme value of $163.6 \Omega \mathrm{cm}^{2}$ at $10^{-3} \mathrm{M}$ of HBHQ. A vast $R_{\mathrm{p}}$ is related with a slower corroding system owing to the lessening in the active surface vital for the corrosion reaction. The estimations of $n$ (ranges from 0.75 to 0.79 ) did not differ significantly, implying that the charge-transfer-controlled dissolution reaction of $\mathrm{CS}$ in $1 \mathrm{M} \mathrm{HCl}$ in the absence and in the presence of HBHQ [31]. Diminishing in the capacitance, this can result from abatement in local dielectric constant or an expansion in the thickness of the electrical double layer, implying that the inhibitor species behave by adsorption at the metal/solution interface [32]. The addition of HBHQ gives lower $C_{\mathrm{dl}}$ values, most likely as a result of substitution 
of water molecules by HBHQ at the steel surface [33]. It is significant that the protection efficiencies got from EIS are practically identical with those got by gravimetric, potentiodynamic polarization tests.

Table 4. Impedance parameters for $\mathrm{CS}$ in $\mathrm{HCl}$ electrolyte with and without various concentrations of HBHQ.

\begin{tabular}{cccccccc}
\hline Medium & $\begin{array}{c}\text { Conc. } \\
(\mathbf{M})\end{array}$ & $\begin{array}{c}\boldsymbol{R}_{\mathbf{s}} \\
\left(\mathbf{\Omega} \mathbf{c m}^{\mathbf{2}}\right)\end{array}$ & $\begin{array}{c}\boldsymbol{R}_{\mathbf{p}} \\
\left(\mathbf{\Omega} \mathbf{~ c m}^{\mathbf{2}}\right)\end{array}$ & $\begin{array}{c}\mathbf{1 0}^{\mathbf{4}} \boldsymbol{A} \\
\left(\mathbf{\Omega}^{-1} \mathbf{s}^{\mathbf{n}} \mathbf{c m}^{\mathbf{2}}\right)\end{array}$ & $\boldsymbol{n}$ & $\begin{array}{c}\boldsymbol{C}_{\mathbf{d l}} \\
\left(\boldsymbol{\mu} \mathbf{F} \mathbf{~ c m}^{-2}\right)\end{array}$ & $\begin{array}{c}\boldsymbol{\eta}_{\Omega} \\
\mathbf{\%})\end{array}$ \\
\hline Blank & 1 & 2.04 & 20.1 & 4.36 & 0.75 & 193.7 & - \\
\hline \multirow{3}{*}{ HBHQ } & $10^{-6}$ & 1.00 & 53.6 & 4.2 & 0.75 & 108.2 & 89 \\
& $10^{-5}$ & 1.12 & 85.6 & 3.2 & 0.77 & 152.2 & 84 \\
& $10^{-4}$ & 1.19 & 120.0 & 3.1 & 0.77 & 162.8 & 79 \\
& $10^{-3}$ & 1.24 & 163.6 & 2.4 & 0.79 & 182.3 & 67 \\
\hline
\end{tabular}

\subsection{Effect of temperature}

By and large, the impact of temperature on the inhibited acid-metal reaction is profoundly intricate, in light of the fact that numerous progressions happen on the metal surface, for example, desorption of inhibitors and the inhibitor itself may experience degradation, rearrangement, substitution or dissolution of complexes formed [34].

In order to enlighten a little this effect, we examined the impact of temperature on the behaviour of the BHHQ inhibitor at a controlled temperature of 298 to $338 \mathrm{~K}$ by gravimetric experiments for $6 \mathrm{~h}$ of immersion. The results of this study are summarized in Table 5.

Table 5. Corrosion parameters concluding from gravimetric experiments for $\mathrm{CS}$ in $\mathrm{HCl}$ electrolyte with and without HBHQ in various temperatures.

\begin{tabular}{ccccc}
\hline Medium & Temp. $(\mathbf{K})$ & $\boldsymbol{C}_{\mathbf{R}}\left(\mathbf{m g} / \mathbf{c m}^{\mathbf{2}} \mathbf{h}\right)$ & $\eta_{g}(\boldsymbol{\%})$ & $\boldsymbol{\theta}$ \\
\hline \multirow{4}{*}{ Blank } & 298 & 0.750 & - & - \\
& 308 & 1.170 & - & - \\
& 318 & 2.550 & - & - \\
& 328 & 4.890 & - & - \\
\hline \multirow{3}{*}{ HBHQ } & 338 & 9.700 & - & - \\
& 298 & 0.060 & 92 & 0.92 \\
& 308 & 0.117 & 90 & 0.90 \\
& 318 & 0.510 & 80 & 0.80 \\
& 328 & 1.467 & 70 & 0.70 \\
& 338 & 4.462 & 54 & 0.54 \\
\hline
\end{tabular}


The protection efficiency decreases and corrosion rate increments with expanding temperature both in uninhibited and inhibited system. The reduction in inhibition efficiency at higher temperatures can be ascribed to desorption of some inhibitor molecules from the CS surface. What's more, makes a more surface area of steel to come in contact with corrosive medium, bringing about an expanded corrosion rate and diminished inhibitory effectiveness [35].

Generally, this behaviour is attributed to the adsorption nature between CS and HBHQ molecule, to determine the type of adsorption, it's required for using the kinetic models.

To estimated activation parameters of the corrosion reaction, Arrhenius Eq. [36].

$$
\begin{gathered}
\ln C_{\mathrm{R}}=\ln K-\frac{E_{\mathrm{a}}}{R T} \\
\text { Slope }=\left(-\frac{E_{\mathrm{a}}}{R T}\right)
\end{gathered}
$$

Where $E_{\mathrm{a}}, R$ and $K$, are apparent activation corrosion energy, gas constant and Arrhenius pre-exponential factor, respectively.

The change of $\ln C_{R}$ as function of 1000/T is established in Figure 6. Concerning the estimation of activation energy $\left(E_{\mathrm{a}}\right)$ for the Schiff's base containing a 5-methyl-8hydroxyquinoline motive is gathered in Table 6 .

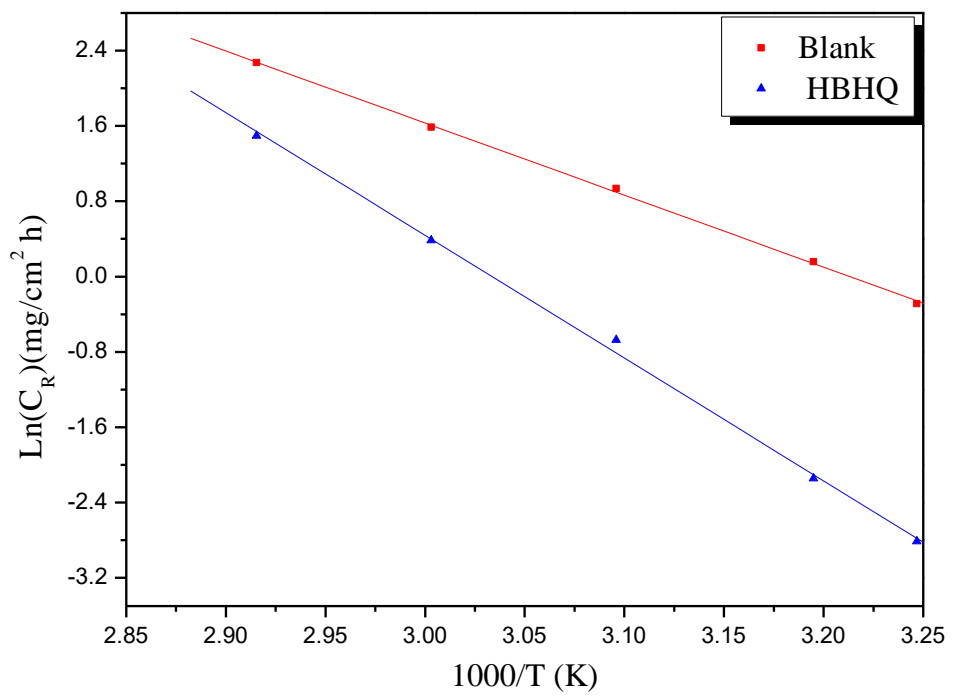

Figure 6. Arrhenius graph for $\mathrm{CS}$ in $\mathrm{HCl}$ electrolyte with and without optimum concentration of HBHQ at studied temperatures. 
Table 6. Kinetic parameters of corrosion for $\mathrm{CS}$ in $\mathrm{HCl}$ electrolyte with and without optimum concentration of HBHQ at studied temperatures.

\begin{tabular}{cccccc}
\hline Medium & $\boldsymbol{K}$ & $\boldsymbol{R}^{\mathbf{2}}$ & $\boldsymbol{E}_{\boldsymbol{a}}(\mathbf{k J} / \mathbf{m o l})$ & $\boldsymbol{\Delta} \boldsymbol{H}_{\mathbf{a}}(\mathbf{k J} \mathbf{J} \mathbf{m o l})$ & $\Delta \boldsymbol{S}_{\mathbf{a}}(\mathbf{J} / \mathbf{m o l ~ K})$ \\
\hline Blank & $4.74 \cdot 10^{10}$ & 0.999 & 63.61 & 60.91 & -49.56 \\
\hline HBHQ & $1.49 \cdot 10^{17}$ & 0.999 & 108.38 & 105.68 & 74.84 \\
\hline
\end{tabular}

The alternative formula of transition state is shown in equation [37],

$$
\begin{aligned}
& \ln C_{\mathrm{R}}=\ln \frac{R T}{N h}+\frac{\Delta S_{\mathrm{a}}}{R}-\frac{\Delta H_{\mathrm{a}}}{R T} \\
& \text { Slope }=\left(-\frac{\Delta H_{\mathrm{a}}}{R}\right) \text { and intercept }=\ln \left(\frac{R}{N h}\right)+\frac{\Delta S_{\mathrm{a}}}{R}
\end{aligned}
$$

Where $h, N, \Delta S_{\mathrm{a}}$ and $\Delta H_{\mathrm{a}}$ are Plank's constant, Avogadro number, the entropy and enthalpy of activation, respectively. The variation of $\mathrm{Ln} C_{\mathrm{R}} / T$ in relation to $1000 / T$ are presented in Figure 7. The extracted $\Delta H_{\mathrm{a}}$ and $\Delta S_{\mathrm{a}}$ values are gathered in Table 6.

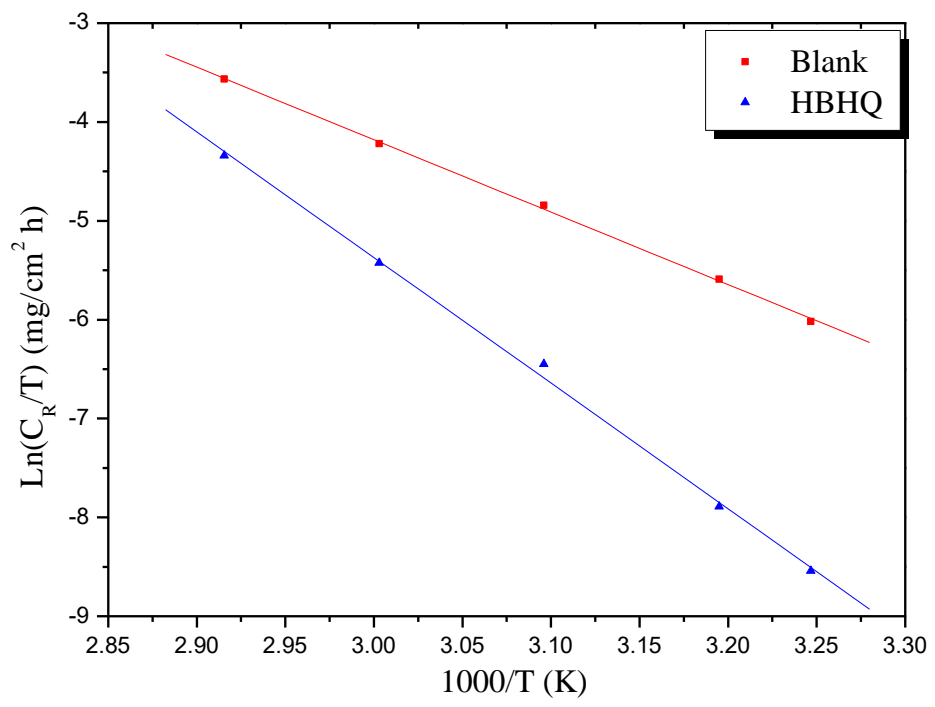

Figure 7. Transition state graph for $\mathrm{CS}$ in $\mathrm{HCl}$ electrolyte with and without optimum concentration of HBHQ at studied temperatures.

The analysis of findings obtained involve that the enthalpies values for dissolution reaction of $\mathrm{CS}$ in $1 \mathrm{M} \mathrm{HCl}$ in the presence of Schiff base containing a 5-methyl-8hydroxyquinoline motive are superior than that of in $\mathrm{HCl}$ electrolyte. However, the $\mathrm{CS}$ dissolution process was defined as endothermic in nature due to the positive signs of $\Delta H_{\mathrm{a}}$. The differentiation amongst physisorption and chemisorption depends on the absolute estimation of $\Delta H_{\mathrm{a}}$. For a physisorption nature the enthalpy of adsorption ought to be 
equivalent to or under $40 \mathrm{~kJ} \mathrm{~mol}^{-1}$ while, for chemisorption it is equivalent to or in excess of $100 \mathrm{~kJ} \mathrm{~mol}^{-1}$ [38]. The calculated value of $\Delta H_{\mathrm{a}}$ for HBHQ is more than $100 \mathrm{~kJ} \mathrm{~mol}^{-1}$ indicate that the adsorption of HBHQ is basically chemisorption.

The value of $E_{\mathrm{a}}$ in presence of synthesized compound is exceeding than the analogous $E_{\mathrm{a}}$ in their absence, this outcome may be due to diminishing in the adsorption of inhibitor molecules on the CS surface with increment in temperature [39]. The current $E_{\mathrm{a}}$ value is marginally up than the enthalpy value and the difference between them has not changed and equal the product $R \cdot T\left(2.62 \mathrm{~kJ} \cdot \mathrm{mol}^{-1}\right)$, indicating that the corrosion process is a unimolecular reaction [40]; this is consonant with prior outcomes characterized by following formula.

$$
R T=E_{\mathrm{a}}-\Delta H_{\mathrm{a}}
$$

In perspective of the entropy results, the addition of HBHQ prompt positive value of entropy, while a negative value is seen in blank media, this increase is coming about because of the ascent in disorder when the reactants are changed to the complex. These outcomes could likewise be clarified by the substitution process of water molecules by adsorption of azomethine molecules at CS surface and thus the increasing in $\Delta S_{\text {a }}$ was allotted to the rise in solvent entropy [41, 42].

\section{Theoretical chemical quantum computation}

\subsection{Global indices derived from the conceptual DFT}

The density functional theory (DFT) has developed a lot these last years. This approach is considered the best method that is interested in studying the reactivity of a molecule and attempt to make a connection with their ability to inhibit metal corrosion. This has been achieved through some chemical quantum descriptors associated with the electronic structure for isolated inhibitory molecules in the gas phase. Quantum computing is done using the method of DFT hybrid, B3LYP, with $6-31++\mathrm{G}(\mathrm{d}, \mathrm{p})$ basis sets implanted in the Gaussian 09W software $[43,44]$. The molecular structure of compound HBHQ is completely optimized. This optimized structure, electrostatic potential (EPS) with surface contour and it's the density distribution of the frontier molecular orbital's (FMO) such as the HOMO (most occupied orbital which owns the highest energy level available to give the electrons) and the LUMO (most unoccupied orbital which is available to accept electrons) are shown in Figure 8. About the graphic images of the distributions of the electron density of the molecular orbital's HOMO and LUMO of our compound (HBHQ) shown in Figure 8 we observe that a large part of the Electron density for the two molecular orbitals HOMO and LUMO is localized at the same time on the molecular surface of methylquinolin-8-ol. This motif can be considered as a very good element that is responsible on the inhibitory efficiency of our compound. 


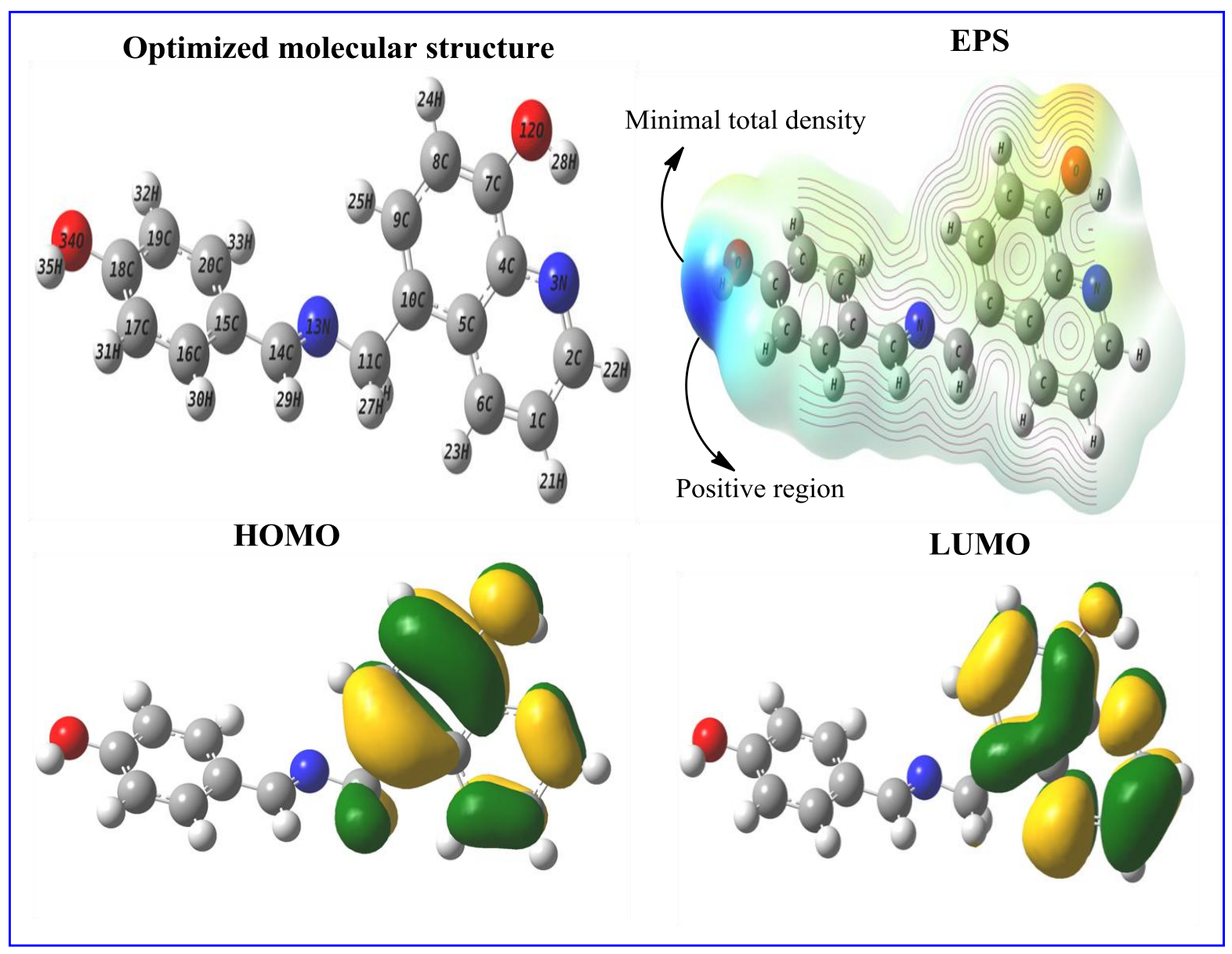

Figure 8. Optimized molecular structure, EPS with surface contour and FMO density distributions of the HBHQ inhibitor.

To correctly describe the overall reactivity of the molecular structure of our compound HBHQ, we are based on some of the major quantum chemical descriptors (QCDs) such as the orbital energies $E_{\mathrm{HOMO}}$ and $E_{\mathrm{LUMO}}$, energy gap $(\Delta E)=\left(E_{\mathrm{LUMO}}-E_{\mathrm{HOMO}}\right)$, dipole moment $(\mu)$, global electronegativity of inhibitor $\left(\chi_{\text {inh }}\right)$, global hardness of inhibitor $\left(\eta_{\text {inh }}\right)$ and the report of electron transferred $\left(\Delta N_{110}\right)$. These indices are calculated using the following equations [44-47].

$$
\begin{gathered}
\chi_{\text {inh }}=-\left(\frac{\partial E}{\partial N}\right)_{v} \\
\eta_{\text {inh }}=0.5\left(\frac{\partial^{2} E}{\partial N^{2}}\right)_{v}
\end{gathered}
$$

Where $E$ is the total energy of inhibitor, $N$ is the number of electrons of inhibitor and $v$ is constant external potential.

According to the approximations that are established in the literature, the $\eta_{\text {inh }}$ and $\chi_{\text {inh }}$ are expressed as follows: 


$$
\begin{gathered}
\eta_{\text {inh }}=0.5\left(E_{\mathrm{LUMO}}-E_{\text {НОМО }}\right)=0.5 \Delta E_{\mathrm{gap}} \\
\chi_{\text {inh }}=-0.5\left(E_{\text {НОмО }}+E_{\text {LUMO }}\right)
\end{gathered}
$$

The value of $\Delta N_{110}$ was calculated using the job function $(\phi)$ that is equal the $4.82 \mathrm{eV}$ in the lattice plane (110) of iron. In addition, $\eta_{\mathrm{Fe}}$ is zero which corresponds the metallic bulk [48].

$$
\Delta N_{110}=\frac{\phi-\chi_{\text {inh }}}{2\left(\eta_{\mathrm{Fe}_{110}}+\eta_{\text {inh }}\right)}=\frac{\phi-\chi_{\text {inh }}}{2 \eta_{\text {inh }}}
$$

The values of these indicators are reported in Table 7. The analysis of the calculated results of this table makes it possible to establish a correlation between the QCPs and the inhibitory power of HBHQ. Indeed, this inhibitor has a significantly high value of $E_{\mathrm{HOMO}}$ $(-5.465 \mathrm{eV})$ and a low value of $E_{\mathrm{LUmO}}(-1.361 \mathrm{eV})$. Knowing that, $E_{\mathrm{HOMO}}$ is often associated with the ability of the molecule give electrons. Where, a molecule with a high $E_{\mathrm{HOMO}}$ value has a tendency to easily give electrons. While, it's the opposite for $E_{\text {Lumo }}$ In other words, the reactivity of a molecule increases with a low value of $\Delta E_{\text {gap }}$, our inhibitor has the value of $\Delta E_{\text {gap }}(4.104 \mathrm{eV})$. In addition, in the context of this theory, it is clear that a molecule becomes more and more reactive with the decrease of its $\eta_{\text {inh }}$ and its $\chi_{\text {inh }}$. HBHQ has values of $\eta_{\text {inh }}(2.052 \mathrm{eV})$ and $\chi_{\text {inh }}(3.413 \mathrm{eV})$. The value of $\Delta N_{110}$ is also listed in Table 7 , the positive value of $\Delta N_{110}(0.343)$ indicates that our inhibitor is capable of transferring electrons to the metal surface of the iron. On the other hand, the high value of dipole moment suggests that the reactivity of this molecule is important.

Table 7. QCDs for two inhibitor neutral HBHQ calculated with the DFT/B3LYP/6-31++G(d,p) method in the gaseous phase.

\begin{tabular}{cccccccc}
\hline Compound & $\boldsymbol{E}_{\text {Hомо }}(\mathrm{eV})$ & $\boldsymbol{E}_{\mathrm{LUMO}}(\mathrm{eV})$ & $\Delta \boldsymbol{E}_{\mathrm{gap}}(\mathrm{eV})$ & $\boldsymbol{\eta}_{\text {inh }}(\mathrm{eV})$ & $\chi_{\text {inh }}(\mathrm{eV})$ & $\Delta \boldsymbol{N}_{110}$ & $\boldsymbol{\mu}(\mathrm{D})$ \\
\hline $\mathrm{HBHQ}$ & -5.465 & -1.361 & 4.104 & 2.052 & 3.413 & 0.343 & 4.888 \\
\hline
\end{tabular}

\subsection{Local indices derived from the conceptual DFT}

It is very important to study the local reactivity of the inhibitor HBHQ in the most predominant form. This study will be conducted through the electrostatic potential (EPS), the net atomic charges (AC) on the atoms using the Natural population analysis (NPA) of Weinhold-Reed analysis and Fukui indices (FI) to determine the site(s) of the HBHQ molecule that interact with the iron surface.

Concerning EPS, it is a method that this potential is created in the space around a molecule by these nuclei or electrons. Indeed, it is indicator of the sites or regions of a molecule which is determined the location of the upper (Red color) and lower (Blue color) electronic densities. The EPS map our compound is represented in the Figure 8. As shown in this figure, the EPS positive region presented by the blue color (poor electron region) is 
located on the oxygen atom (O34). In addition, on the rest of the skeleton of the molecule tested, the regions lie with poor or rich densities.

Table 8. $f_{i}(\vec{r})^{+}$and $f_{i}(\vec{r})^{-}$functions and atomic charges calculated for HBHQ compound.

\begin{tabular}{cccc}
\hline Atoms & $f_{i}(\vec{r})^{+}$ & $f_{i}(\vec{r})^{-}$ & Net atomic charges \\
\hline $\mathrm{C}(1)$ & 0.026 & 0.028 & -0.039 \\
\hline $\mathrm{C}(2)$ & 0.047 & 0.031 & 0.047 \\
\hline $\mathrm{N}(3)$ & 0.032 & 0.043 & -0.208 \\
\hline $\mathrm{C}(4)$ & 0.046 & 0.030 & 0.151 \\
\hline $\mathrm{C}(5)$ & 0.053 & 0.005 & 0.118 \\
\hline $\mathrm{C}(6)$ & 0.029 & 0.024 & -0.051 \\
\hline $\mathrm{C}(7)$ & 0.049 & 0.033 & 0.365 \\
\hline $\mathrm{C}(8)$ & 0.034 & 0.061 & -0.117 \\
\hline $\mathrm{C}(9)$ & 0.030 & 0.026 & -0.053 \\
\hline $\mathrm{C}(10)$ & 0.036 & 0.033 & 0.085 \\
\hline $\mathrm{C}(11)$ & 0.012 & 0.014 & -0.046 \\
\hline $\mathrm{O}(12)$ & 0.046 & 0.116 & -0.457 \\
\hline $\mathrm{N}(13)$ & 0.012 & 0.075 & -0.297 \\
\hline $\mathrm{C}(14)$ & 0.015 & 0.009 & 0.053 \\
\hline $\mathrm{C}(15)$ & 0.047 & 0.007 & 0.167 \\
\hline $\mathrm{C}(16)$ & 0.006 & 0.005 & -0.050 \\
\hline $\mathrm{C}(17)$ & 0.006 & 0.046 & -0.112 \\
\hline $\mathrm{C}(18)$ & 0.016 & 0.013 & 0.403 \\
\hline $\mathrm{C}(19)$ & 0.006 & 0.006 & -0.085 \\
\hline $\mathrm{C}(20)$ & 0.004 & 0.001 & -0.2051 \\
\hline $\mathrm{O}(34)$ & 0.018 & 0.018 &
\end{tabular}

The other local descriptors most used to determine the local reactivity of a molecule are atomic charges and Fukui indices. The values of these indicators of compound HBHQ are distributed in Table 8 . We have admitted that the more the atom is positively charged, its ability to accept electrons is maximal. So, this atom is considered as an electron acceptor site. Whereas, an atom has a larger atomic charge, it is considered an electron donor site. The results in Table 8 show that the atoms $\mathrm{C} 4, \mathrm{C} 5, \mathrm{C} 5, \mathrm{C} 7, \mathrm{C} 15$ and $\mathrm{C} 18$ are electron receptor sites. While, the atoms $\mathrm{N} 3, \mathrm{C} 8, \mathrm{O} 12, \mathrm{~N} 13$ and $\mathrm{C} 17$ are able to give 
electrons (available to fix the protons). To be more precise in the determination and confirm acceptors-donors sites of electron for HBHQ, we used the Fukui functions $f(\vec{r})$. The latter is the first derivative of the electronic density $\rho(\vec{r})$ :

$$
f(\vec{r})=\left(\frac{\partial \rho(\vec{r})}{\partial N}\right)_{v(\vec{r})}
$$

The Fukui functions $f_{i}(\vec{r})^{-}$and $f_{i}(\vec{r})^{+}$are calculated as follows:

$$
\begin{array}{ll}
f_{i}(\vec{r})^{+}=\rho_{N+1}(\vec{r})-\rho_{N}(\vec{r}) & \text { For a nucleophilic attack } \\
f_{i}(\vec{r})^{-}=\rho_{N}(\vec{r})-\rho_{N-1}(\vec{r}) & \text { For an electrophilic attack }
\end{array}
$$

These functions of HBHQ were calculated and collated in Table 8 using the Materials Studio 2016 software from Biovia-Accelrys Inc., using a GGA exchange-correlation functional in the $\mathrm{Dmol}^{3}$ module with the polarization function DNP.

It's obvious that a compound that has many of the atoms with high values of the $f_{i}(\vec{r})^{+}$ and $f(\vec{r})^{-}$functions, it has a great chance to adsorb on the surface of the iron and considered a good inhibitor of corrosion. The results in Table 8 show that the HBHQ compound has several disoponible active sites to give electrons with a high density of $f_{i}(\vec{r})^{-}$, we quote the atoms $\mathrm{N} 3, \mathrm{C} 8, \mathrm{O} 12, \mathrm{~N} 13$ and $\mathrm{C} 17$. While, the atoms $\mathrm{C} 4, \mathrm{C} 5, \mathrm{C} 5, \mathrm{C} 7$, $\mathrm{C} 15$ and $\mathrm{C} 18$ are the most favorable sites to accept electrons. Indeed, these atoms have enriched the molecular structure of HBHQ for well adsorbed on the surface of metal.

It is very important to notice that the results obtained for the three methods used in this section are comparable.

\section{3. $H B H Q$ inhibitor protonated}

In this section, we studied the protonation effect of compound HBHQ to determine its overall reactivity. In this context and in the previous section (Local indices derived from the conceptual DFT) we found that the nitrogen atom N13 is considered as the favorable site for protonation. Indeed, the atom N13 has the high value of $f_{i}(\vec{r})^{-}$such as 0.075 ; this center is able to fix protons $\left(\mathrm{H}^{+}\right)$. Results obtained are regrouped in the Table 9, from this table we showed that values of all the descriptors are more displaced after to the protonation of the studied compound. Indeed, the values of $\mathrm{E}_{\text {номо }}$ and $\Delta \mathrm{N}_{110}$ are shifted to more intense and less negative values. This indicates that the protonated compound can accept electrons in a more important way. This result reflects that the proton forms behave like Lewis acids. While, the decrease in the value of $\Delta \mathrm{E}_{\text {gap }}$ and the increase in the dipole moment value show that the overall reactivity of HBHQ is becoming greater. So, the adsorbate-substrate interactions occur in a reasonable way. 
Table 9. QCDs for two inhibitor protonated HBHQ calculated with the DFT/B3LYP/6-31++G(d,p) method in the gaseous phase.

\begin{tabular}{cccccccc}
\hline Compound & $\boldsymbol{E}_{\text {HOмо }}(\mathbf{e V})$ & $\boldsymbol{E}_{\mathrm{LUMO}}(\mathrm{eV})$ & $\Delta \boldsymbol{E}_{\mathrm{gap}}(\mathrm{eV})$ & $\boldsymbol{\eta}_{\text {inh }}(\mathrm{eV})$ & $\chi_{\text {inh }}(\mathrm{eV})$ & $\Delta \boldsymbol{N}_{\mathbf{1 1 0}}$ & $\boldsymbol{\mu}(\mathrm{D})$ \\
\hline $\mathrm{HBHQ}$ & -9.445 & -7.803 & 1.642 & 0.821 & 8.624 & -2.317 & 11.70 \\
\hline
\end{tabular}

\section{Study of structural reactivity via the Monte Carlo method}

Monte Carlo simulation (MCs) is a method of molecular mechanics used as a simulation tool less costly at the level of the calculation time, on one side, to quantify the interaction energy $\left(\mathrm{E}_{\text {int }}\right)$ molecule inhibitor and the metal surface, and on the other side, to find the best stable adsorption configuration. In this framework and for our work we used very adequate calculation conditions. This has been calculated taking into account the reactions that occur in a $1 \mathrm{M} \mathrm{HCl}$ medium in the presence of the HBHQ compound.

Indeed, in MCs we were interested in studying the behavior of the system (Surface Fe (110)/HBHQ inhibitor in an aggressive acid environment with $5\left(\mathrm{H}_{3} \mathrm{O}^{+}, \mathrm{Cl}^{-}\right)$and $500 \mathrm{H}_{2} \mathrm{O}$. This simulation was done using done using Forcite tools and adsorption Locator tools implanted in the Materials Studio 2016 software. The inhibitor used is optimized before placing it in the iron cell to minimize his energy energie using the Generalized Gradient Approximation (GGA) exchange-correlation functional in the Dmol ${ }^{3}$ module with the polarization function DNP. On the other hand, the simulation box of Fe consisted of a 6 floors of iron atoms split along the (110) plane in the simulation cell $(29.78 \AA / 29.78 \AA /$ $30.13 \AA)$ with periodic boundary conditions. A super cell of $(13 \times 13)$ for increase the covering area of the $\mathrm{Fe}(110)$ was created and a vacuum of $19.30 \AA$ was mounted above the surface of the iron. The all system in equilibrium with the most predominant and most stable configuration is represented in Figure 9. This figure shows that azomethine derivative namely 5-(((4-hydroxybenzylidene)amino)methyl)quinolin-8-ol (HBHQ) is positioned in parallel above the metal surface of the iron. In addition, the adsorption of our compound on the metal substrate is means that this inhibitor contains active attractor and donor active sites that promotes its adsorption.

To see the type of interaction we tried to determine the distances (lengths) between the heteroatom of tested inhibitor and the atoms of iron. Generally, the length of the physical nature bonds (physisorption) is greater than $3.5 \AA$, while, the length of the bonds of chemical nature (chimisorption) appears in the interval of $1 \AA-3.5 \AA$ (Xie et al., 2015). As shown in Figure 9, the distances between the heteroatoms ( $\mathrm{N}$ and $\mathrm{O}$ ) of our compound HBHQ and the atoms of the metal surface are lower $3.5 \AA$. This shows that our inhibitor adsorbs chemical way (chemisorption). 


\section{Side view}

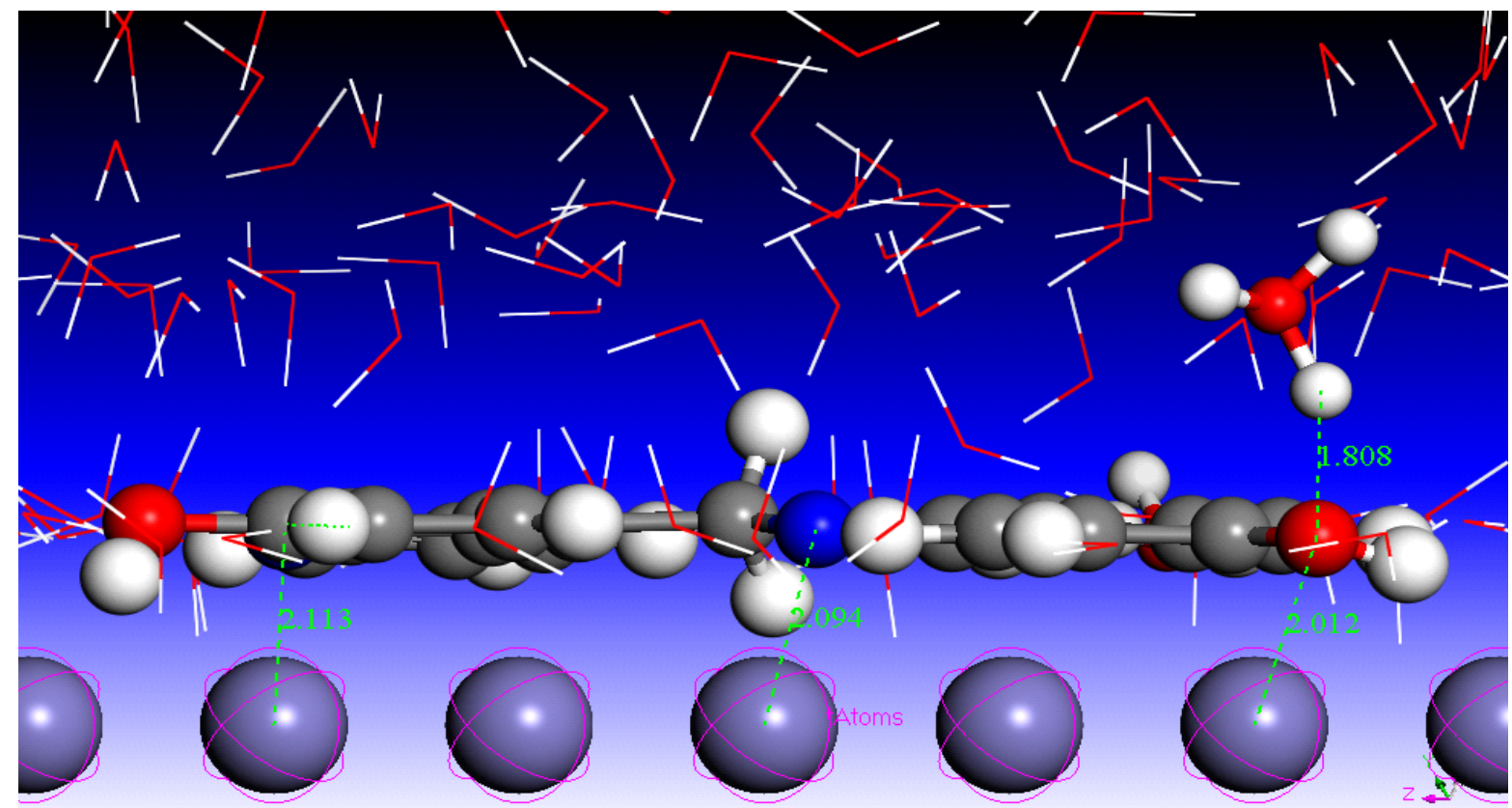

\section{Superior view}

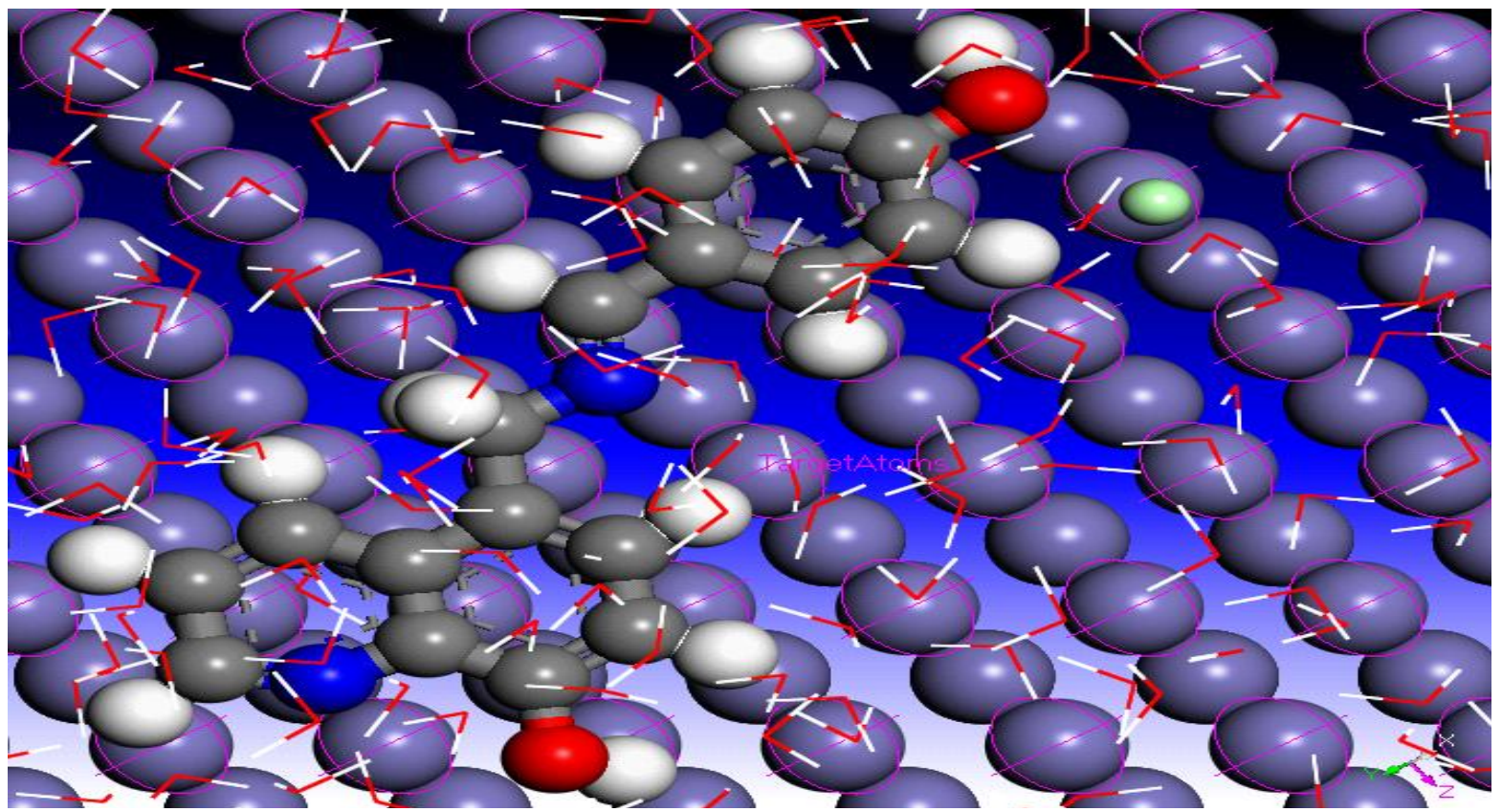

Figure 9. Equilibrium adsorption configuration of the azomethine derivative (HBHQ) on the $\mathrm{Fe}(110)$ surface in solution obtained by MCs.

A quantitative analysis concerning the energy indicators was calculated such as the total energy $\left(E_{\mathrm{tot}}\right)$, deformation energy $\left(E_{\mathrm{def}}\right)$ the adsorption $\left(E_{\mathrm{ads}}\right)$ and interaction $\left(E_{\mathrm{int}}\right)$ energy $\left(E_{\mathrm{ads}}=-E_{\mathrm{int}}\right)$. When the system studied in equilibrium, all the energy term values are grouped in Table 10. We notice from the analysis of the data of the results obtained in 
this table, it may be noted that $E_{\text {ads }}(-5541.602 \mathrm{Kcal} / \mathrm{mol})$ energy values are negative. This indicates that the adsorption process is exothermic nature [49]. In addition, the more negative value of $E_{\text {tot }}(-5489.680 \mathrm{Kcal} / \mathrm{mol})$ reflects that the adsorption could occur spontaneously [49]. The high value of deformation energy $\left(E_{\mathrm{def}}=119.2073 \mathrm{Kcal} / \mathrm{mol}\right)$ shows a great deformation in the geometry of the components of the studied system. This can be attributed to the presence of the active centers of adsorption on the metal surface of the iron oxidized [50]. The calculated value of the interaction energy ( $E_{\text {int }}=5541.602$ $\mathrm{Kcal} / \mathrm{mol}$ ) is higher. This suggests that the HBHQ inhibitor is well adsorbed on the surface of the substrate. Indeed, this result shows that our compound is a good inhibitor as indicated in the experimental part.

Table 10. Values of energy quantities for $\mathrm{Fe}(110) / \mathrm{HBHQ} / 500 \mathrm{H}_{2} \mathrm{O} / 5\left(\mathrm{Cl}^{-}, \mathrm{H}_{3} \mathrm{O}^{+}\right)$system. (All values in $\mathrm{Kcal} / \mathrm{mol})$.

\begin{tabular}{ccccc}
\hline Compound & $\boldsymbol{E}_{\text {tot }}$ & $\boldsymbol{E}_{\text {ads }}$ & $\boldsymbol{E}_{\text {int }}$ & $\boldsymbol{E}_{\text {def }}$ \\
\hline HBHQ & -5489.680 & -5541.602 & 5541.602 & 119.207 \\
\hline
\end{tabular}

\section{Conclusion}

The newly Azomethine derivative was firstly synthesized and characterized by usually spectroscopic techniques, and in a second time the HBHQ was examined using both practical and theoretical approaches for their anticorrosion properties of carbon steel in the hydrochloride acid electrolyte. The outcomes demonstrated that HBHQ have great inhibitory effectiveness for the corrosion of carbon steel in $1 \mathrm{M} \mathrm{HCl}$ and that their protection was more articulated at $10^{-3} \mathrm{M}$. The high inhibition efficiency of HBHQ was credited to the adsorption of inhibitor molecules on the metal surface. The Tafel polarization bends showed that HBHQ restrain both anodic metal dissolution and the cathodic hydrogen development reaction. EIS experiments depict that the charge transfer resistance increases and double layer capacitance decreases in the presence the HBHQ, affirming the adsorption of inhibitor molecules on the CS surface. The adsorption of HBHQ molecules on the metal surface from acidic media follows the Langmuir isotherm. Regarding the side theoretical, the overall reactivity of our compound (HBHQ) has been discussed by quantum chemical descriptors and the local reactivity shows that HBHQ contain several reactive sites responsible for the inhibitor / metal interactions. Monte Carlo simulations show that the compound HBHQ is well adsorbed on the surface of the metal.

\section{Acknowledgement}

The authors wish to thank the "Moroccan Ministry of Higher Education" for providing all the facilities and for supporting this work.

\section{Competing interests}

Authors have declared that no competing interests exist. 


\section{References}

1. T. Zhu, L. Wang, W. Sun, Z. Yang, S. Wang, Y. Zhou and G. Liu, Ind. Eng. Chem. Res., 2018, 57, no. 14, 5183-5189.

2. M. El Faydy, M. Galai, M. Rbaa, M. Ouakki, B. Lakhrissi, M. Ebn Touhami and M. El Kacimi, Anal. Bioanal. Electrochem., 2018, 10, no. 7, 815-839.

3. M. El Faydy, M. Galai, R. Touir, A. El Assyry, M.E. Touhami, B. Benali and A. Zarrouk, J. Mater. Environ. Sci., 2016, 7, no. 4, 1406-1416.

4. A. Zarrouk, H. Zarrok, R. Salghi, R. Touir, B. Hammouti, N. Benchat, L.L. Afrine, H. Hannache, M. El Hezzat and M. Bouachrine, J. Chem. Pharm. Res., 2013, 5, no. 12, 1482-1491.

5. M. Rbaa, M. Galai, M. El Faydy, Y. El Kacimi, M.E. Touhami， A. Zarrouk and B. Lakhrissi, Anal. Bioanal. Electrochem., 2017, 9, no. 7, 904-928.

6. I.B. Obot, S.A. Umoren, Z.M. Gasem, R. Suleiman, B. El Ali, J. Ind. Eng. Chem., 2015, 21, 1328-1339.

7. H. Zarrok, A. Zarrouk, R. Salghi, M. Ebn Touhami, H. Oudda, B. Hammouti, R. Touir, F. Bentiss and S.S. Al-Deyab, Int. J. Electrochem. Sci., 2013, 8, 6014-6032.

8. H. Zarrok, R. Salghi, A. Zarrouk, B. Hammouti, H. Oudda, Lh. Bazzi, L. Bammou and S.S. Al-Deyab, Der Pharma Chem., 2012, 4, no. 1, 407-416.

9. M. Abdallah, H.M. Eltass, M.A. Hegazy and H. Ahmed, Prot. Met. Phys. Chem. Surf., 2016, 52, no. 4, 721-730.

10. K.C. Emregül and O. Atakol, Mater. Chem. Phys., 2004, 83, no. 2-3, 373-379.

11. G.P. Cicileo, B.M. Rosales, F.E. Varela and J.R. Vilche, Corros. Sci., 1998, 40, no. 11, 1915-1926.

12. M. El Faydy, R. Touir, M.E. Touhami, A. Zarrouk, C. Jama, B. Lakhrissi and F. Bentiss, Phys. Chem. Chem. Phys., 2018, 20, no. 30, 20167-20187.

13. H. Gerengi, M. Mielniczek, G. Gece and M.M. Solomon, Ind. Eng. Chem. Res., 2016, 55, no. 36, 9614-9624.

14. D.M. Jamil, A.K. Al-Okbi, S.B. Al-Baghdadi, A.A. Al-Amiery, A. Kadhim, T.S. Gaaz and A.B. Mohamad, Chem. Cent. J., 2018, 12, no. 7, 1-9.

15. P. Dohare, M.A. Quraishi and I.B. Obot, J. Chem. Sci., 2018, 130, no. 8, 1-19.

16. F. Tezcan, G. Yerlikaya, A. Mahmood and G. Kardaş, J. Mol. Liq. 2018, 269, 398-406.

17. M. El Faydy, M. Galai, M.E. Touhami, I.B. Obot, B. Lakhrissi and A. Zarrouk, J. Mol. Liq., 2017, 248, 1014-1027.

18. A.S.T.M. Standard G1-03, Standard practice for preparing, cleaning, and evaluating corrosion test specimens, Annual Book of ASTM Standards, 2003, vol. 3, pp. 17-25.

19. H. About, M. El faydy, Z. Rouifi, F. Benhiba, H. Ramsis, M. Boudalia, H. Zarrok, H. Oudda, R. Touir, M. El M'Rabet, I. Warad, A. Guenbour and B. Lakhrissi, J. Mater. Environ. Sci., 2018, 9, 345-357.

20. I.B. Obot, N.K. Ankah, A.A. Sorour, Z.M. Gasem and K. Haruna, Sustainable Mater. Technol., 2017, 14, 1-10. 
21. A. Yousefi, S.A. Aslanzadeh and J. Akbari, Anti-Corros. Methods Mater., 2018, 65, no. $1,107-122$.

22. H. Ouici, M. Tourabi, O. Benali, C. Selles, C. Jama, A. Zarrouk and F. Bentiss, J. Electroanal. Chem., 2017, 803, 125-134.

23. H. Tayebi, H. Bourazmi, B. Himmi, A. El Assyry, Y. Ramli, A. Zarrouk, A. Geunbour, B. Hammouti and E.E. Ebenso, Der Pharm. Lett., 2014, 6, no. 6, 20-34.

24. M. El Faydy, M. Galai, A. El Assyry, A. Tazouti, R. Touir, B. Lakhrissi and A. Zarrouk, J. Mol. Liq., 2016, 219, 396-404.

25. T.T. Phan, F. Bentiss and C. Jama, New J. Chem., 2018, 42, no. 16, 13442-13452.

26. K. Zhang, B. Xu, W. Yang, X. Yin, Y. Liu and Y. Chen, Corros. Sci., 2015, 90, 284295.

27. A. Zarrouk, B. Hammouti, T. Lakhlifi, M. Traisnel, H. Vezin and F. Bentiss, Corros. Sci., 2015, 90, 572-584.

28. A. Zarrouk, H. Zarrok, Y. Ramli, M. Bouachrine, B. Hammouti, A. Sahibed-dine and F. Bentiss, Inhibitive properties, J. Mol. Liq., 2016, 222, 239-252.

29. M. Tourabi, K. Nohair, A. Nyassi, B. Hammouti, C. Jama and F. Bentiss, J. Mater. Environ. Sci., 2014, 5, no. 4, 1133-1143.

30. R. Mehdaoui, A. Khelifa, A. Khadraoui, O. Aaboubi, A.H. Ziane, F. Bentiss and A. Zarrouk, Res. Chem. Intermed., 2016, 42, no. 6, 5509-5526.

31. N. Yilmaz, A. Fitoz and K.C. Emregül, Corros. Sci., 2016, 111, 110-120.

32. P. Mourya, S. Banerjee and M.M. Singh, Corros. Sci., 2014, 85, 352-363.

33. M.H.O. Ahmed, A.A. Al-Amiery, Y.K. Al-Majedy, A.A.H. Kadhum, A.B. Mohamad and T.S. Gaaz, Results Phys., 2018, 8, 728-733.

34. X. Chen, W. Tian, S. Li, M. Yu and J. Liu, Chin. J. Aeronaut., 2016, 29, no. 4, 11421150.

35. D.B. Hmamou, R. Salghi, A. Zarrouk, H. Zarrok, R. Touzani, B. Hammouti and A. El Assyry, J. Environ. Chem. Eng., 2015, 3, no. 3, 2031-2041.

36. L.O. Olasunkanmi, B.P. Moloto, I.B. Obot and E.E. Ebenso, J. Mol. Liq., 2018, 252, $62-74$.

37. T. Douadi, H. Hamani, D. Daoud, M. Al-Noaimi and S. Chafaa, J. Taiwan Inst. Chem. Eng., 2017, 71, 388-404.

38. A. Popova, M. Christov and A. Vasilev, Corros. Sci., 2015, 94, 70-78.

39. B. Tan, S. Zhang, Y. Qiang, L. Guo, L. Feng, C. Liao and S. Chen, J. Colloid Interface Sci., 2018, 526, 268-280.

40. F. Bentiss, M. Lebrini and M. Lagrenée, Corros. Sci., 2005, 47, no. 12, 2915-2931.

41. H. Tayebi, H. Bourazmi, B. Himmi, A. El Assyry, Y. Ramli, A. Zarrouk, A. Geunbour and B. Hammouti, Der Pharma Chem., 2014, 6, no. 5, 220-234.

42. E.A. Noor and A.H. Al-Moubaraki, Mater. Chem. Phys., 2008, 110, no. 1, 145-154.

43. F. Benhiba, H. Zarrok, A. Elmidaoui, M. El Hezzat, R. Touir, A. Guenbour, A. Zarrouk, S. Boukhris and H. Ouddaa, J. Mater. Environ. Sci., 2015, 6, no. 8, 23012314. 
44. M.J. Frisch, G.W. Trucks, H.B. Schlegel, G.E. Scuseria, et al., Gaussian 09, Revision A.01, Gaussian, Inc., Wallingford CT, 2009.

45. L.O. Olasunkanmi, M.M. Kabanda and E.E. Ebenso, Physica E Low Dimens. Syst. Nanostruct., 2016, 76, 109-126.

46. L.O. Olasunkanmi, I.B. Obot, M.M. Kabanda, E.E. Ebenso, J. Phys. Chem. C, 2015, 119, 16004-16019.

47. R.G. Pearson, Inorg. Chem., 1988, 27, 734-740.

48. V. Sastri and J. Perumareddi, Corrosion, 1997, 53, 617-622.

49. M.M. Kabanda, I.B. Obot and E.E. Ebenso, Int. J. Electrochem. Sci., 2013, 8, 1083910850.

50. M.F. Chiter, Theoretical study of green corrosion inhibitors: adsorption of 8hydroxquinoline on aluminum surface, National Polytechnic Institute of Toulouse, University of Toulouse, Toulouse, France, 2015. 